\title{
RECEPCIÓN DEL DECRETO CONCILIAR «OPTATAM TOTIUS» EN LAS CONFERENCIAS GENERALES DEL EPISCOPADO LATINOAMERICANO**
}

Fecha de recepción: 28 de abril de 2021

Fecha de aceptación: 29 de junio de 2021

RESUMEN: Esta publicación se aboca a la recepción que las últimas conferencias generales del episcopado latinoamericano y caribeño han hecho de Optatam totius, el documento conciliar que aborda la formación del clero. Da una especial importancia a Medellín, pues esta debió ser la conferencia que debía actualizar la enseñanza conciliar en el continente, expectativa que cumplió al dedicar al tema un capítulo entero. Medellín, no obstante sus límites, demandó que se capacitara a los seminaristas en el discernimiento de los signos de los tiempos. Sin embargo, las siguientes conferencias de Puebla, Santo Domingo y Aparecida se fueron alejando progresivamente de esta innovación y del decreto mismo del Concilio. Por tanto, no ha de afirmarse fácilmente que la Iglesia de América Latina y el Caribe haya hecho una recepción creativa de Optatam totius, como suele decirse de la recepción latinoamericana del Vaticano II en general.

PALABRAS CLAVE: Optatam totius; formación del clero; Medellín; recepción del Vaticano II.

\footnotetext{
* Centro Teológico Manuel Larrain: jcostado@uc.cl;

ORCID: https://orcid.org/0000-0002-3364-9899

** Este texto se enmarca en el proyecto de investigación Fondecyt N. ${ }^{\circ} 1190556$ (Chile).
} 


\section{Reception of the Conciliar Decree "Optatam Totius" in the General Conferences of the Latin American Episcopate}

ABSTRACT: This publication addresses the acceptance from the latest general Latinamerican and Caribbean episcopal conferences to the Optatam Totius. This document refers to the formation of the clergy. It gives particular importance to Medellín's conference as it has updated the conciliar teaching in the continent and dedicated a full chapter to the topic. Notwithstanding its limits, Medellín claimed the need for supporting seminarians in discerning the "signs of the times". However, subsequent conferences such as Puebla, Santo Domingo and Aparecida progressively moved away from the innovation proposed by Medellín and the Second Vatican Council's decree. Therefore, we should not think that the Latinamerican and Caribbean Churches have accepted Optatam Totius creatively as it usually appears in the Latinamerican discussions regarding the Second Vatican Council.

KEY WORDS: Optatam totius; formation of the clergy; Medellín; reception of Vatican II.

\section{INTRODUCCIÓN}

La recepción de Optatam totius (OT) en América Latina tiene dos ámbitos. Uno es el de la implementación del decreto conciliar en los seminarios y casas de formación. Es decir, el ámbito práctico. Este artículo no tratará de éste. En cambio, se abocará al campo de los documentos. En estas materias se distinguen los textos de los teólogos y las llamadas rationes, éstas son los documentos que las conferencias episcopales nacionales han debido redactar sobre la formación del clero ${ }^{1}$, como lo manda hacer Optatam totius. En esta investigación, empero, se indagará en una tercera clase de textos, los de los obispos de las conferencias episcopales de Medellín, Puebla, Santo Domingo y Aparecida².

La división de dos partes de esta investigación se justifica porque ha sido Medellín la conferencia que ha debido ocuparse in recto de la recepción del Concilio en América Latina. Las otras conferencias también lo han hecho. Por ello, la recepción de Optatam totius se enriquece si se

\footnotetext{
1 Sobre esta materia convendrá consultar el artículo de Ricardo Mauti "La recepción de Optatam totius en las rationes de la Iglesia de América Latina”, en vías de publicación.

2 Rodrigo Polanco. "Concepto teológico de recepción con vistas a su aplicación al desarrollo posterior al Concilio Vaticano II”. Teología y vida 54 (2013): 224; Rodrigo Coppe Caldeira. "O Concílio Vaticano II, sua hermenêutica e recepção". Estudos teológicos 55, n. ${ }^{\circ} 1$ (2015): 60-75.
} 
da importancia a Medellín en relación a la recepción que los documentos de Puebla, Santo Domingo y Aparecida fueron haciendo, o no, de la II Conferencia.

Por de pronto conviene advertir que el concepto de recepción, no siendo el objeto de este estudio, constituye el horizonte de la búsqueda ${ }^{3}$. Por esto se hace necesario decir una palabra a su respecto. En esta investigación se tendrá en cuenta que, antes que ser fieles a textos, la recepción en teología es sobre todo la acogida del Evangelio que la Iglesia proclama por generaciones. En el caso de los escritos que lo transmiten, estos son letra muerta mientras la Iglesia no se convierta a lo que Dios quiere decirle en el presente ${ }^{4}$. La Tradición de la Iglesia es la recepción el Evangelio ${ }^{5}$. Lo es en virtud del Espíritu que le hace ser fiel a lo recibido del pasado y a la anticipación creativa que ella haga del acontecimiento escatológico. La creatividad es inherente a cualquier recepción. La recepción es una actividad eclesial espiritual antes que fidelidad a los textos que la hacen inteligible. El texto rige la comprensión del Evangelio, pero el Evangelio, a su vez, funge de criterio de interpretación, en nuestro caso, del texto conciliar. Éste, en la medida en que es un documento espiritual, estimula

3 Cf. Pedro Trigo. "Recepción del Vaticano II a los cincuenta años de su apertura". Iter 23, n. ${ }^{\circ}$ 57-58 (2012): 15-23; Víctor Codina. "Recepción del Concilio Vaticano II en América Latina". Mensaje 62, n. 625 (2013): 28-29; José Aldunate. "Recepción del Concilio Vaticano II por la Iglesia Chilena”. Reflexión y liberación 26, n. ${ }^{\circ} 107$ (2015): 16-21; Alfonso Guerrero. "La recepción del Concilio en América Latina”. Iter, n. 1 (1995): 35-46; Ernesto Valiente. "The reception of the Vatican II in Latin America”. Theological Studies n. 73 (2012): 823; Robert Pelton. "The reception of Vatican II in Latin America: A North American perspective". Theological Studies 74, n. ${ }^{\circ} 4$ (2013): 824-823; Rafael Luciani. "Medellín fifty years later: From development to liberation”. Theological Studies 79, n. ${ }^{\circ} 3$ (2018): 566-89; José de Jesús Legorreta Zepeda. "La recepción latinoamericana del Concilio en los documentos de las conferencias generales del episcopado latinoamericano: de Medellín a Aparecida”. Christus 77, n. 802 (2014): 11-20; Richard Arce. "Concilio Vaticano II - 50 años: el proceso de su recepción en América Latina”. Nuevamérica, n. 137 (2013): 24-29; Virginia Azcuy. "La recepción del Concilio Vaticano II en el pueblo de Dios. Testimonios sobre la renovación desde las formas de vida”. Revista Teología 50, n. ${ }^{\circ} 112$ (2013): 203-49; J. Míguez Bonino. "The Reception of Vatican II in Latin America”. Oicumene 37, n. 3 (1985): 266-74.

4 Cf. Eduardo Silva. "Paul Ricoeur y los desplazamientos de la hermenéutica". Teología y vida 46 (2005): 191-196.

5 Cf. Jorge A. Scampini y Carlos Federico Schickendantz. La recepción teológica del Concilio Vaticano II. Buenos Aires: Agape-Guadalupe, 2015, 43. 
nuevas experiencias y nuevos textos que las contengan. De aquí que los abusos en la interpretación del Concilio pueden referirse a un irrespeto de sus documentos, pero también a una falta de creatividad.

En este estudio se han tenido en cuenta criterios de recepción extraídos obviamente de los mismos documentos conciliares. Por ejemplo, la prioridad que Presbyterorum ordinis (4) y Optatam totius (4) dan al deber de los sacerdotes de anunciar la Palabra en la formación de los seminaristas, y a la formación bíblica correspondiente (Optatam totius 16). Se ha atendido también a la estrecha relación pedida entre los estudios de filosofía y teología como condición para comprender el mundo actual y dialogar con los contemporáneos (Optatam totius 14-15).

También se considerará la perspectiva que ofrece el estudio de los consilia et vota que los obispos latinoamericanos enviaron a Roma con motivo de la convocación del Vaticano II, lo mismo que sus intervenciones durante el Concilio ${ }^{6}$. Otro antecedente conciliar útil es el documento de la I Conferencia general de episcopado reunida en Río de Janeiro (1955). En él se dan orientaciones importantes para la formación del clero. Las comparaciones entre el tiempo anterior y posterior al Concilio ayudan a evaluar el sentido de los cambios.

Asimismo, ayudará la consideración que se haga de las normas creadas por las conferencias episcopales nacionales contenidas en las rationes en las últimas cinco décadas. Una pregunta importante a este respecto es acaso éstas, y las mismas conferencias posteriores a Medellín, han hecho suyo o no el texto de Optatam totius. En todo caso, es de mencionar la enorme importancia que ha tenido en este periodo Pastores dabo vobis ${ }^{7}$.

En fin, al momento de discernir la fidelidad de la Iglesia latinoamericana a las sugerencias y requerimientos de Optatam totius, debe considerarse la recepción en conjunto que esta Iglesia ha hecho del Concilio. Bien parece que en la recepción regional del Vaticano II los asuntos en cuestión han podido influirse unos a otros y, por lo mismo, los frutos más importantes también debieran hacer de criterios de juicio. Por esto se tendrá en cuenta aquí la «opción por los pobres». Esta representa simbólicamente la recepción que la Iglesia en América Latina ha hecho del Vaticano II ${ }^{8}$.

6 Cf. Jorge Costadoat. "Contribución de los obispos latinoamericanos a la confección de Optatam totius”. Teología y Vida 62, n. ${ }^{\circ} 3$ (2021): 389-423.

7 Cf. supra, Mauti, investigación en curso de publicación.

8 Cf. Valiente. "The reception of the Vatican II in Latin America", 823; Pelton. "The reception of Vatican II in Latin America: A North American perspective”, 824-823; 
Cabe, en consecuencia, preguntarse en qué medida se ha querido que en la formación del clero tenga un lugar la práctica de la caridad y la lucha por la justicia en estas conferencias. La Iglesia latinoamericana misma, sus comunidades y los esfuerzos teológicos por reflexionar su situación histórica a la luz de la Palabra de Dios, ha entendido que es esencial hacer suyos los sufrimientos y las alegrías de los latinoamericanos (GS 1). Si esto no fuera decisivo en la formación del clero, habría que sospechar que algo falla. La opción por los pobres es un lugar de observación muy importante para la recepción de Optatam totius en América Latina.

\section{LA RECEPCIÓN DE OPTATAM TOTIUS EN EL DOCUMENTO SO- BRE LA FORMACIÓN DE MEDELLÍN ${ }^{9}$}

El documento n..$^{\circ} 13$ de Medellín titulado Formación del clero (en adelante Formación), unas veces hace recepción explícita de OT, refiriendo a sus textos; otras, sin hacerlo de un modo explícito, se inspira en este documento. El objeto de nuestro artículo hace necesario avisar la existencia de otros capítulos de Medellín como son los dedicados a los sacerdotes (n. $\left.{ }^{\circ} 11\right)$ y a los religiosos (n. $\left.{ }^{\circ} 12\right)$.

En esta sección de la investigación se da cuenta de la dependencia más relevante de este documento $\mathrm{n}^{\circ} 13$ respecto de OT. Otros vínculos y tópicos serán simplemente mencionados. La conexión más profunda entre ellos es dar una orientación decididamente pastoral a la formación del clero (Formación 1 y 21). En este sentido, ambos textos están en línea con la intención de aggiornamento del Concilio ante el desafío pastoral

\footnotetext{
Luciani. "Medellín fifty years later: From development to liberation”, 566-89; Legorreta. "La recepción latinoamericana del Concilio en los documentos de las conferencias generales del episcopado latinoamericano: de Medellín a Aparecida”, 11-20; Arce. "Concilio Vaticano II - 50 años: el proceso de su recepción en América Latina", 24-29; Azcuy. "La recepción del Concilio Vaticano II en el pueblo de Dios. Testimonios sobre la renovación desde las formas de vida”, 203-49; Míguez Bonino. "The Reception of Vatican II in Latin America", 266-74.

9 Cf. Agenor Brighenti. "Vaticano II - Medellín: intuições básicas e eixos fundamentais”. Revista eclesiástica brasileira 69, n. 273 (2009): 5-26; Fernando Verdugo. "Relectura de Medellín: desafíos actuales para la teología". Teología y vida 59 (2018): 111-28; Francisco Taborda. "A conferencia de Medellín como recepção do Vaticano II”. Perspectiva Teológica 51, n. ${ }^{\circ} 1$ (2019): 115-32.
} 
que significa anunciar el Evangelio en las nuevas circunstancias históricas y ofrecer orientaciones pastorales a las Iglesias de cada nación ${ }^{10}$.

\subsection{HORIZONTE HISTÓRICO}

El mero título de la Conferencia de Medellín ayuda a interpretar el documento sobre la formación del clero: "Presencia de la Iglesia en la actual transformación de América Latina". El documento Formación es encabezado por una cita de Pablo VI. "América Latina presenta una sociedad en movimiento, sujeta a cambios rápidos y profundos [Pablo VI, 23/11/65]». Continúa el documento, especificando la tarea que compete a la Iglesia del continente: «Esto repercute sobre la misma Iglesia y le exige una postura frente a esa situación. La Iglesia Latinoamericana debe expresar su testimonio y su servicio en este continente, enfrentado con problemas tan angustiosos como los de la integración, desarrollo, profundos cambios y miseria» (Formación 1). En esta cita resuena una preocupación central presente en los otros documentos de Medellín. En América Latina, al igual que en los años del Concilio, se constata que un gran signo de los tiempos son los enormes cambios o transformaciones en todos los planos de la existencia humana; en el continente, ellos se expresan particularmente en cambios sociales ${ }^{11}$.

El documento Formación desea responder derechamente a la situación histórica. Sus autores, los obispos latinoamericanos, son conscientes de los problemas que la Iglesia tiene para enfrentar este desafío. A saber, escasez de sacerdotes y de vocaciones sacerdotales ${ }^{12}$, y necesidad de formar ministros capaces de cumplir esta misión en este contexto y no en otro.

\subsection{FoRMACIÓN PARA «INTERPRETAR LOS SIGNOS DE LOS TIEMPOS»}

El documento Formación contiene la mejor expresión de su criterio hermenéutico en estos términos:

\footnotetext{
10 Cf. OT Proemio, 1, 15, 16, 19.

11 Cf. Medellín, Pastoral de las élites, 13.

12 Formación, 1. En el documento Sacerdotes (3) no sólo se lamenta la escasez, sino la mala distribución del clero. Dedica, además, unas palabras a las personas que dejaron el ministerio (30).
} 
«Procúrese en el seminario una reflexión continua sobre la realidad que vivimos, a fin de que se sepan interpretar los signos de los tiempos, y se creen actitudes y mentalidad pastorales adecuadas [OT 4; Ecclesiam suam 25]» (Formación 26) ${ }^{13}$.

Esta exigencia de capacitar a los seminaristas para «interpretar los signos de los tiempos», explica que Formación, en otro lugar, eche en falta un «equilibrio para discernir lo positivo de lo negativo en las novedades que surgen dentro de la vida de la Iglesia y del mundo» (Formación 4) ${ }^{14}$.

A efecto de discernir los signos de los tiempos se pide a la formación conceder mucha importancia al conocimiento de la Sagrada Escritura ${ }^{15}$. Los seminaristas deben desarrollar la «capacidad para escuchar fielmente la Palabra de Dios» (Formación 10). El estudio de las Escrituras en Medellín se ordena a la praxis:

«Se pide al sacerdote de hoy saber interpretar habitualmente, a la luz de la fe, las situaciones y exigencias de la comunidad. Dicha tarea profética exige, por una parte, la capacidad de comprender, con la ayuda del laicado, la realidad humana y, por otra, como carisma específico del sacerdote en unión con el obispo, saber juzgar aquellas realidades en relación con el plan de salvación» (Formación 10) ${ }^{16}$.

También la formación en ciencias humanas y en filosofía posee este mismo interés por responder al contexto histórico de aquellos años: «Hoy más que nunca es urgente actualizar los estudios de acuerdo con las orientaciones del Concilio, insistiendo en aquellos aspectos que atañen

13 Resuenan aquí los textos de GS sobre estos signos de los tiempos (GS 4, 11, 44). También en PO la referencia a los «signos de los tiempos» es importante (PO 28). En las «ponencias» de inauguración de la Conferencia el tema es clave. La expresión también está presente en el documento Sacerdotes (28) de Medellín. Lo destacado con letra itálica es propio.

14 Lo destacado es propio.

15 Debe recordarse el lugar prioritario que OT 16 da al estudio de la Sagrada Escritura. Le llama «alma de la teología». Es de mencionar, además, que los consiglia et vota de los obispos latinoamericanos también daban importancia a este tema. Los Obispos de México entienden que las Sagradas Escrituras constituyen «el meollo de la teología» (AS III, VII, 946). Cf. Antonio Barbieri, ADAP I/II, VII, 541; Manuel Marengo, ADAP I/II, VII, 50; Carlos Hartl, ADAP I/II, VII, 383; Juan T. Senner, ADAP I/II, VII, 108; Ignacio de Alba y Hernández, ADAP I/II, VI, 178; Enrique Angelelli, AS III/VIII, 245.

16 Cf. OT 4, 8, 16. Lo destacado es propio. 
más particularmente a la situación actual del continente» (16 ${ }^{17}$. Es esta intención pastoral la que hace decir a los obispos de Medellín: «Dése una importancia particular al estudio e investigación de nuestras realidades latinoamericanas en sus aspectos religioso, social, antropológico y sicológico» $(18)^{18}$.

Este requerimiento a la formación de capacitar personas para que puedan conocer la realidad hace que Medellín pida de los formadores y de los formandos una práctica pastoral. En el caso de éstos, se demanda prepararlos «en algunos aspectos de particular importancia en nuestro continente latinoamericano: formación básica sobre Pastoral de conjunto, preparación para la iniciación y asistencia de las comunidades de base, conveniente información y entrenamiento en dinámica de grupos y relaciones humanas, información adecuada para la utilización de los medios de comunicación social [IM 16]» (Formación 21).

\subsection{Presupuesto cristológico}

Cristo es, para Medellín, el fundamento de una formación sacerdotal a la altura de los tiempos; es el criterio y la condición del discernimiento de los signos de los tiempos para el cual los seminaristas han de ser preparados. Según el documento Formación:

«El sacerdote, como Cristo, está puesto al servicio del pueblo. Esto pide de él, aceptar sin limitaciones las exigencias y las consecuencias del servicio a los hermanos y, en primer lugar, la de saber asumir las realidades y "el sentido del pueblo" en sus situaciones y en sus mentalidades. Con espíritu de humildad y de pobreza, antes de enseñar debe aprender, haciéndose todo a todos para llevarlos a Cristo [OT 4, 19; Pablo VI, Ecclesiam suam passim; Bogotá, 22/08/68]» (Formación 13) ${ }^{19}$.

A este propósito cabe notar que Formación, al igual que OT, no habla del sacerdote como de alter Christus o de un ministro que actúa in

17 Lo destacado es propio. Cf. Consiglia et vota: Conferencia de obispos de Colombia, AS II/II, VII, 943; Conferencia de obispos de México, AS II/II, VII, 946; Eduardo Pironio, AS III/VIII, 326; Alfredo Silva Santiago, ADAP I/II, VII, 355; Analyticus conspectus consiliorum, ADAP-1l-1, 626.

18 Lo destacado es propio.

19 Lo destacado es propio. 
persona Christi, denominaciones corrientes en los años anteriores al Concilio. La expresión «como Cristo» de la cita anterior es interesante, pues pone en relación al ministro con las realidades del mundo actual y con el pueblo de Dios. Es más, pide de él una apertura tal que, en vez de enseñar a este pueblo, debiera disponerse a aprender humildemente de él y de los tiempos. La expresión paulina de hacerse «todo a todos» abre la posibilidad teológica de llegar a encontrar a Cristo en los otros y de ser evangelizados por los pobres ${ }^{20}$.

Además de esta indicación fundamental, el documento Formación establece que el seminario tiene como «razón de ser» hacerse cargo del «llamado»y de la «respuesta» de las vocaciones sacerdotales. Medellín, a este propósito, da como criterio central de la formación sacerdotal la «configuración» de los seminaristas con «Cristo cabeza». Es así que pide de éstos llegar a ser «conductores de hombres». Ésta es su tarea específica en relación al resto del pueblo de Dios. Su identidad, como enseña el Concilio, difiere de la de los demás bautizados esencialmente y no sólo en grado. Pero él no es ya el Sumo y eterno sacerdote al servicio de un sacrificio, sino un "pastor» (Formación 17) que guía a su pueblo con "caridad pastoral». Es ésta la que, en última instancia, justifica el celibato. El motivo central de éste es «la entrega a Cristo y con él a la Iglesia». De aquí que se hace necesario dar a los seminaristas unas «bases muy sólidas para vivirlo (el celibato) gozosamente en la plenitud del amor» (Formación 12).

\subsection{OMISIONES IMPORTANTES}

En dependencia de OT, Medellín también da importancia a otras materias como, por ejemplo, a la capacidad para oír los llamados de Dios en general (24), a las vocaciones de compromiso con la Iglesia (25), a los sacerdotes extranjeros (30) y al trabajo en equipo (12). Medellín da enorme relevancia a la pastoral vocacional (23-25; cf. OT 12) y a los seminarios mayores (5-6). A los seminarios menores les dedica un número discreto (6b) en comparación con Puebla (870-872) y Santo Domingo (81). Aparecida, por su parte, no los menciona.

El documento n. ${ }^{\circ} 13$, sin embargo, tiene omisiones mayores en relación a OT y a la realidad eclesial de aquellos años. Es necesario señalarlas.

20 Cf. Puebla 910.

ESTUDIOS ECLESIÁSTICOS, vol. 97, núm. 380, marzo 2022, 45-71, ISSN 0210-1610, ISSN-e 2605-5147 
- El documento latinoamericano no recoge la innovación conciliar de hacer del ministerio de la Palabra el principal de los ministerios sacerdotales. Es sabido que la discusión sobre el orden de los tria munera no fue casual. Expresamente se quiso que la proclamación del Evangelio (propia del profeta) fuera la primera responsabilidad del ministro ordenado. A ésta seguiría la del culto (propia del sacerdote) y en último lugar la del gobierno (propia del rey). Esta novedad propia de PO y OT, respecto de tiempos en los cuales la identidad del sacerdote estribaba en la celebración de la eucaristía, fue enorme ${ }^{21}$.

- Tal vez Formación refleja este cambio de un modo implícito. Reconoce, por cierto, decisivo el estudio de las Sagradas Escrituras. Sin embargo, esto no justifica que del servicio sacramental de los sacerdotes no se diga nada. El documento nunca menciona la eucaristía $^{22}$. No habla del culto, del sacrificio, de los sacramentos, de la cruz ni del misterio pascual. Por cierto, este fallo ha podido enervar a católicos que, hasta estos últimos años, han visto la II Conferencia con malos ojos. Tal vez sean estas omisiones las que explican que Medellín no haya sido recibido por las siguientes conferencias episcopales, ni por las normas que las conferencias episcopales se han dado para la formación de los seminaristas, más que a modo de respetuoso saludo ${ }^{23}$.

- El documento n. ${ }^{\circ} 13$ de Medellín tampoco hace mención a la estrecha relación que OT quiso dar al estudio de la filosofía y la teología. Sabemos que ésta es una de las condiciones fundamentales de la articulación de fe y razón, y de fe y cultura, sin la cual no es posible dialogar con la realidad contemporánea y los compromisos de la Iglesia en los cambios sociales tan queridos por Formación ${ }^{24}$. De la teología el documento no hace más que dos

21 Cf. Gilles Routhier. "L'écho de l'enseignement de Vatican II sur le prestytérat dans la situation actuelle”. Revue Théologique de Louvain 41 (2010): 106.

22 Alguna vez se refiere a la «liturgia» (10).

23 Esta conclusión se extrae del artículo de Ricardo Mauti mencionado anteriormente (cf. supra nota 2).

${ }^{24}$ Cf. Grant Kaplan. "The renewal of ecclesiastical studies: Chenu, Tübingen, and Theological Method in Optatam totius". Theological Studies 77, n. ${ }^{\circ}$ (2016): 587-589. Robert Barron. "The reception of Vatican II: A Book Excerpt by bishop Robert Barron". https:/www.wordonfire.org/resources/blog/the-reception-of-vatican-ii-a-book-excerpt-by-bishop-robert-barron/18627 Consultado 22/04/2021. 
menciones rápidas, pero nada dice de la necesaria interrelación de ésta con las ciencias sociales y la filosofía.

- Este documento no menciona nunca a Jesús de Nazaret, a su anuncio del reino a los pobres ${ }^{25}$ y a los motivos de su muerte. La denominación más importante, a su respecto, es la de "Cristo». Debe decirse que, si como criterio de interpretación del Concilio la Iglesia latinoamericana ha hecho de la opción por los pobres su principal motivación, la cual encuentra en el mismo documento de Medellín una fuente decisiva (Cf. Documento sobre La pobreza de la Iglesia), llama la atención que Formación ignore esta referencia.

- Nunca Formación menciona a las mujeres. Es anacrónico demandárselo. Pero se trata de una falta que merece ser advertida en un documento tenido por progresista, ya que la exclusión de las mujeres en la Iglesia constituye un ejemplo subcontrario de las señales históricas de la voluntad de Dios.

\subsection{CONCLUSIÓN}

Hasta aquí ha podido verse que la recepción que Medellín hace de OT es compleja. En términos generales puede decirse que el documento sobre la Formación del clero es fiel a OT en los asuntos fundamentales. Visto todo en la clave de aggiornamento pastoral, este documento se deja llevar por OT. Lo cita a menudo. Lo más relevante es que continúa el impulso renovador que el texto conciliar le dio. Medellín desea formar sacerdotes que colaboren en la misión de la Iglesia de discernir en los acontecimientos históricos regionales la presencia de Dios.

Pero, como se ha visto, el documento no hace una mención explícita de una innovación conciliar clave. Omite referirse al reordenamiento de los tria munera en beneficio del deber del ministro ordenado de anunciar el Evangelio característico de PO y OT; olvida la importancia de su servicio sacramental y en especial la celebración de la Eucaristía; no relaciona estrechamente los estudios de las ciencias sociales, la filosofía y la teología, herramientas sin las cuales ha debido ser imposible discernir

25 Llama la atención que Medellín en este documento nunca mencione a los pobres, siendo que en otros documentos ellos constituyen un tópico fundamental. 
los signos de los tiempos; nada dice del Jesús de la historia y de su opción por los pobres; no menciona a los laicos ni a las mujeres.

En defensa de Formación el documento expresamente sostiene: «De acuerdo con lo anterior, teniendo en cuenta la situación latinoamericana, y sin pretender agotar todos los aspectos de la formación, que por otra parte se hallan contenidos en los documentos del Concilio Vaticano II y de la Santa Sede, ofrecemos a continuación algunas orientaciones pastorales» (Formación 8). El documento ha hecho una selección de asuntos en vista de encaminar la formación del clero en una dirección muy determinada.

\section{RECEPCIÓN DE OPTATAM TOTIUS EN PUEBLA, SANTO DOMINGO Y APARECIDA}

\subsection{Puebla sigue aún la Senda de Medellín}

La III Conferencia del Episcopado de América Latina realizada en Puebla (1979), a diferencia de Medellín, no tiene un capítulo aparte sobre la formación. Sólo dedica a ésta una sección sobre los seminarios (869-891), además de otros textos esparcidos en el documento ${ }^{26}$. En éste hay dos temas relevantes a propósito de la formación del clero. Uno tiene relación con OT; el otro está muy presente en Medellín.

Puebla no tiene por objeto una recepción particular de OT, como la tiene Medellín, pero ciertamente se inspira en el Vaticano II en su conjunto. Por de pronto, para Puebla es relevante que la formación de los sacerdotes esté al servicio de "la renovación de toda la Iglesia», intención clave en el Proemio de OT (Puebla 708). Fuera de ésta, otras menciones de OT son prácticamente inexistentes ${ }^{27}$.

El documento de Puebla sintoniza con OT en la preocupación compartida por la pastoral vocacional ${ }^{28}$. La considera tarea prioritaria (885). En la sección dedicada a los seminarios, el documento dedica a ella diez números (881-891). En estos la III Conferencia hace un llamado particular a promover las vocaciones entre los campesinos, el mundo obrero y los grupos étnicos marginados (886); lo mismo que en los medios

26 Cf. 85, 716, 762-764, 781, 875, 1003, 1233.

27 Sólo se da una en 4,3, y refiere a OT 3.

28 Cf. OT 2-3, 8, 12 
profesionales y universitarios (887). Además, demanda una promoción de las vocaciones misioneras (891). En todos los casos, Puebla pide que la pastoral vocacional sea «encarnada», es decir, que tenga en cuenta "el actual momento histórico de América Latina» (884).

El asunto más importante, sin embargo, tiene que ver in recto con la formación del clero. La siguiente cita resume bien los asuntos que Puebla releva:

«El Seminario Mayor, inserto en la vida de la Iglesia y del mundo, de acuerdo con las normas y orientaciones precisas de la Santa Sede, tiene como objetivo el acompañar el pleno desarrollo de la personalidad humana, espiritual y pastoral, es decir, integral de los futuros pastores. Éstos con una fuerte experiencia de Dios y una clara visión de la realidad en que se encuentra América Latina, en íntima comunión con su Obispo, Maestro de la verdad y con los otros Presbíteros, han de ser los que evangelicen, animen y coordinen los diferentes carismas del pueblo de Dios en orden a la construcción del Reino» $(875)^{29}$.

Un tópico que guarda continuidad estricta con Medellín, y que debe considerarse un énfasis latinoamericano en la materia, es la exigencia de inserción de la formación en la Iglesia y la «realidad» del continente, para lo cual es necesario que los seminarios ofrezcan a los formandos la posibilidad de adquirir una «clara visión de la realidad en que se encuentra América Latina». En OT (15-16) la orientación pastoral es decisiva. Puebla no llega a precisar, como lo hace Medellín, que los seminaristas deban ser capacitados para discernir los «signos de los tiempos», pero ambas conferencias comparten esta solicitud pastoral de ubicar la Iglesia a su época. Un segundo asunto es la demanda de Puebla de una formación «integral» («pleno desarrollo de la personalidad humana, espiritual y pastoral»), también importante en Medellín y tema relevante en OT que distingue varios aspectos tales como la formación espiritual, intelectual y pastoral. Por último, es de notar el deseo de la Conferencia de la preparación de los futuros sacerdotes para conducir a otros al interior del Pueblo de Dios, siempre en relación con la «construcción del Reino», lo que por entonces significaba anticipar la realización escatológica en el presente histórico (226-231).

Al igual que en Medellín, en Puebla hay aspectos importantes ausentes acerca de la formación de los seminaristas. En el documento existe

29 Destacados propios. 
una sola mención a la eucaristía; nunca se refiere a Jesús ni a Cristo y, en consecuencia, nada dice del Cristo cabeza y pastor; no menciona la cruz, ni el sacrificio de Cristo, ni a la resurrección, ni el misterio pascual. Tampoco alude a la preparación de los futuros sacerdotes para impartir los sacramentos. En una ocasión habla de la necesaria reforma de la ratio studiorum, pero no toca el tema de la teología ni de la filosofía ni de las ciencias humanas, salvo para demandar formación de los sacerdotes en lo que atañe a los medios de comunicación. Por último, en la sección sobre la formación no hace mención del sacerdocio común de los fieles, aunque lo menciona en otras partes del documento ${ }^{30}$.

En defensa de Puebla debe decirse que ha podido descansar en las principales directrices teológicas y pastorales de OT, además de otros documentos de la Santa Sede sobre la materia publicados después de Medellín ${ }^{31}$.

\subsection{La inculturación incompleta de Santo Domingo}

El documento de la IV Conferencia del Episcopado Latinoamericano realizada en Santo Domingo (1992) aporta algunas novedades respecto de las conferencias anteriores. En ningún caso pretende romper con lo aseverado en éstas. Declara fidelidad a Medellín, Puebla y el Concilio. Pero también es ligeramente nuevo en algunos puntos.

Santo Domingo, a semejanza de Puebla, tampoco elaboró un capítulo aparte sobre la formación del clero. En unos pocos números, sin embargo, le dedica espacio. Por lo mismo, al igual que la III Conferencia, no puede pedírsele un desarrollo completo de lo que la Iglesia latinoamericana espera de la formación de los seminaristas. Por ejemplo, el documento en los números respectivos no menciona a Cristo ni al reino; nunca habla del sacrificio, de la cruz, de la resurrección, ni del misterio pascual de Cristo; tampoco hace alusión a la Palabra, a la Biblia o las Escrituras; no hace ninguna referencia al sacerdocio común de los fieles, como tampoco en el resto del documento; la teología, la filosofía y las ciencias

\footnotetext{
30 En 269 y 681 recuerda el distinto nivel del sacerdocio común respecto del sacerdocio ministerial y en 588 explica en positivo en qué consiste.

31 Cf. Sagrada Congregación para la Educación Católica. "Normas básicas para la formación sacerdotal”. Roma, 1970.
} 
humanas no son tema. De hecho, en esta sección, nunca cita OT. Pero bien puede decirse que, como Puebla y Medellín, descansa en la novedad de OT respecto de la concepción de la formación anterior al Vaticano II.

Sobre la materia, da importancia a dos asuntos: a las vocaciones y a los seminarios. Un punto bastante novedoso respecto de las anteriores conferencias, incluida la de Río de Janeiro, es la constatación que hace Santo Domingo sobre un rebrote de las vocaciones sacerdotales (83). El documento celebra este hecho y también el desarrollo de la pastoral vocacional, haciendo un llamado a fortalecerla, pues los jóvenes presentan características culturales nuevas. Para Santo Domingo, acerca de las vocaciones al sacerdocio, es «muy importante»:

«Estructurar una pastoral vocacional inserta ${ }^{32}$ en la pastoral orgánica de la diócesis, en estrecha vinculación con la pastoral familiar y la juvenil. Es urgente preparar agentes y encontrar recursos para este campo de la pastoral y apoyar el compromiso de los laicos en la promoción de vocaciones consagradas» (80).

No existe en esta cita, como ocurre en otras similares de las conferencias anteriores, un requerimiento explícito de atención a la realidad histórica en la formación del clero. La «inserción» que se desea es «en la pastoral orgánica de las diócesis», antes que en la realidad histórica. Así las cosas, el impulso en aras de una «Nueva evangelización» impulsada por Juan Pablo II merece ser examinado. Ésta, como el empeño por una inculturación del Evangelio subrayada por Santo Domingo, da qué pensar. El sacerdote evangelizador debiera poder ser evangelizado por las gentes de su época.

Otra diferencia respecto de las conferencias anteriores, además de este aire de optimismo por el retorno de las vocaciones, constituye la mención explícita de los sacramentos de la eucaristía, la penitencia y la confirmación en los seminarios menores. También para Santo Domingo un «signo de alegría y de esperanza es el nacimiento de seminarios mayores en nuestro continente» (83). En continuidad con las conferencias anteriores y con OT en particular, la IV Conferencia procura la formación integral de los seminaristas (84). Preocupa, asimismo, tener formadores de calidad, a efecto de lo cual sugiere aprovechar los cursos del CELAM y asumir las «Normas básicas para la formación sacerdotal» que los episcopados han debido elaborar (84).

\footnotetext{
32 Destacado propio.
} 
Santo Domingo, es de destacar, se deja orientar por Pastores dabo vobis (70 y 84). Este hecho representa un giro involutivo que por aquella época ya se había dado en los seminarios latinoamericanos y que a futuro se consolidó.

\subsection{El retroceso de Aparecida}

La V Conferencia General del Episcopado realizada en Aparecida, Brasil (2007), al igual que Puebla y Santo Domingo dedica una breve sección a la formación del clero, trece números en total.

La intención última de Aparecida, resumida en su título "Discípulos y misioneros de Jesucristo para que en Él tengan vida", se aplica perfectamente a la pastoral vocacional y a la formación de los seminaristas (316). Por de pronto, ambos asuntos, ser «discípulos» y «misioneros», han de considerarse inseparables. Pero queda planteada una pregunta: ¿cuánto aprende del mundo el misionero que ha de proclamar el Evangelio? El documento no pone en relación a los seminaristas con los pobres, de quienes algo pudieran ellos aprender.

En fidelidad con la intención pastoral del Concilio, desde Medellín hasta Aparecida la intención de la Iglesia es evangelizar el continente. Pero, bien parece que a la conferencia brasilera no le interesa adiestrar a los seminaristas en el discernimiento de los signos de los tiempos. Antes bien, la V Conferencia, en los números relativos a la formación de los seminaristas, quiere prepararlos para enfrentar un mundo hostil. Aparecida llama a los jóvenes a abrirse a la posibilidad de una «llamada de Dios al sacerdocio o a la vida consagrada, no obstante los problemas generados por una cultura secularizada, centrada en el consumismo y el placer» (315). El Señor les ayudará a asumir este desafío. Asimismo, del proceso de formación se espera que los candidatos al sacerdocio alcancen la madurez propia de quien hace suyo un "proyecto de vida estable y definitivo, en medio de una cultura que exalta lo desechable y lo provisorio» (321). A los formadores en los seminarios les exige «mayor atención a los proyectos formativos», porque:

«Los jóvenes son víctimas de la influencia negativa de la cultura postmoderna, especialmente de los medios de comunicación social, trayendo consigo la fragmentación de la personalidad, la incapacidad de asumir compromisos definitivos, la ausencia de madurez humana, 
el debilitamiento de la identidad espiritual, entre otros, que dificultan el proceso de formación de auténticos discípulos y misioneros» (318).

La visión de mundo en la que Aparecida coloca la formación de los seminaristas es negativa. El documento no invita a discernir en los acontecimientos y en la cultura la acción de Dios que, eventualmente, pudiera ser proseguida por los sacerdotes.

Estudios preliminares ${ }^{33}$ indican que Pastores dabo vobis (1992) —exhortación apostólica que revierte la innovación conciliar en un punto importante ${ }^{34}$ - ha tenido un enorme impacto en la formación y, según parece, incide en Aparecida. Los obispos en esta ocasión presentaron a Cristo como Buen pastor, pero no articularon los tria munera al modo como lo hicieron PO y OT. De acuerdo al documento, el seminarista tendría que llegar a ser "signo personal y atractivo de Cristo en el mundo» (316). En otras palabras, nuevamente se hace depender la misión de la Iglesia de la identidad y de la santidad del presbítero ${ }^{35}$. En vez de conjugar la identidad del futuro sacerdote en el ejercicio del ministerio profético, sacerdotal y real de Cristo, se la establece en relación a su persona al igual que se hacía antes del Concilio.

Otros asuntos a mencionar de estos números de Aparecida dedicados a la formación del clero son: la necesidad de favorecer un crecimiento integral de los seminaristas centrado en la figura de Jesucristo Buen Pastor (319); la importancia del testimonio y preparación de los formadores (317); el requisito de una opción personal, libre y madura de los seminaristas

33 Se alude a la mención hecha más arriba sobre el trabajo de Ricardo Mauti.

34 Según Gilles Routhier, tras la publicación de Pastores dabo vobis y el Directorio para el ministerio y la vida de los sacerdotes (1994), se ha dado una inflexión en la reflexión. Ésta «insiste cada vez más en la identidad del sacerdote y en su espiritualidad. De un modo progresivo, el presbiterado es concebido como un estado más que como un ministerio. Por desplazamientos sucesivos, se vuelve a considerar el presbiterado, que se designa más y más a partir de la categoría sacerdotal, como un estado de perfección. Después de cincuenta años, prácticamente se ha invertido la perspectiva señalada por el Vaticano» (Routhier, "Les décrets Presbyterorum ordinis et Optatam totius", 35-36).

35 Aparecida explicita con fuerza la diferencia entre el sacerdocio común y el sacerdocio ministerial: «El sacerdote no puede caer en la tentación de considerarse solamente un mero delegado o sólo un representante de la comunidad, sino un don para ella por la unción del Espíritu y por su especial unión con Cristo cabeza» (193). Interesa notar en esta cita que la V Conferencia intenta frenar un proceso de identificación de los sacerdotes con los laicos. 
por el sacerdocio, todo lo cual debieran fomentarlo los seminarios (322); el deber del seminario de ofrecer «una formación intelectual seria y profunda», en el que el estudio de la Sagrada Escritura debiera tener un lugar relevante (323); la formación para la vida comunitaria, la cual exige el cultivo de varios valores humanos comenzando por el del diálogo (324); el cuidado de una formación inculturada para «jóvenes provenientes de familias pobres o de grupos indígenas» (325); la necesidad de complementar la formación del seminario con la formación permanente (326); $\mathrm{y}$, en tiempos de escasez de vocaciones, la necesidad de desarrollar la pastoral vocacional (314-315).

Todos estos requerimientos tan positivos, no deben ocultar el sutil desacato a OT señalado más arriba, el cual ha podido advertirse en la resacralización del clero latinoamericano sufrida por el Pueblo de Dios, por los agentes pastores y, en especial, por las religiosas.

Por último, hacemos notar que Aparecida, como tampoco Puebla y Santo Domingo, ponen a los seminaristas en relación con la opción por los pobres que ha caracterizado la recepción latinoamericana del Concilio.

\section{CONTRAPUNTO: RÍO DE JANEIRO}

Tras revisar la recepción que las conferencias episcopales latinoamericanas II a V del documento OT, conviene, a modo de contrapunto, recordar lo que la I Conferencia General del Episcopado de América Latina, reunida en Río de Janeiro (1955), planteaba acerca de la formación del clero $^{36}$. Esto ayuda a ver en perspectiva las diferencias en la recepción latinoamericana posterior del Vaticano II.

Una preocupación central de la Iglesia en América Latina preconciliar, pero que continuará presentándose bajo otros respectos en los documentos de las conferencias latinoamericanas, es la escasez de clero. Ésta merece de Río una "campaña en favor de las vocaciones sacerdotales», pues el problema es grave y trascendente (4). Esta inquietud debe contextualizarse en la relación de cristiandad que por entonces aún predominaba

36 Cf. J. Costadoat. "La formación teológica en América Latina antes del Concilio”. Estudios Eclesiásticos 95, n. ${ }^{\circ} 373$ (2020): 441-455. 
entre Iglesia y sociedad ${ }^{37}$. Hasta antes del Vaticano II todavía tuvo fuerza la idea de una unidad bastante indiferenciada entre ambos, de modo que el clero aún pudo entonces sentirse llamado a adoctrinar y a corregir los errores doctrinales, que se daban en una sociedad que se suponía cristiana. En este contexto, la necesidad de sacerdotes era vista como un asunto fundamental:

«El apostolado de los laicos no debe reducirse únicamente a colaborar con el sacerdote en el campo limitado de los actos de piedad, sino que, además de un esfuerzo continuo por conservar y defender íntegramente la fe católica, debe ser un apostolado misionero de conquista para la dilatación del reino de Cristo en todos los sectores y ambientes, y particularmente allí donde no pueda llegar la acción directa del sacerdote» (Río, Conclusiones 45) ${ }^{38}$.

Para la I Conferencia General del Episcopado, el protagonista de la acción eclesial es el sacerdote. Los laicos colaboran con él, prolongando su acción hasta donde éste no pueda llegar. La misión ad extra, de acuerdo a esta cita, consiste en una "conquista», una extensión del Reino de Cristo a todos los planos de la vida humana, principalmente de un modo doctrinal ("para conservar y defender íntegramente la fe católica»).

La conferencia de Río de Janeiro, en relación a la recepción latinoamericana de OT, llama la atención por la idea que ella tiene de la identidad del sacerdote. A propósito de la pastoral vocacional, Río convoca a una «intensa propaganda que dé a conocer a las almas la grandeza del Sacerdocio y la importancia capital de la labor formativa que se realiza en los seminarios» (5) ${ }^{39}$. Tratándose de los jóvenes que ya han ingresado al seminario, Río espera que éstos lleguen a imitar a Jesucristo, Sumo y Eterno Sacerdote, «inculcando, especialmente en los estudiantes de teología, la convicción práctica de la grandeza del apostolado sacerdotal y de la necesidad y posibilidad de santificarse en él, enseñándoles que el propio ministerio pastoral es fuente de santificación y de perfección» $(14)^{40}$. Con todo, en el documento de Río no están presentes los conceptos de in persona Christi o de alter Christus referidos al sacerdote, tan propios de

37 Paulo Suess. "Sinais dos tempos". En Dicionário do Concílio Vaticano II, 895-901. São Paulo, 2015.

38 Destacado propio.

39 Destacado propio.

40 Destacado propio. 
la Iglesia preconciliar ${ }^{41}$. Por cierto, en las conferencias latinoamericanas examinadas anteriormente no hay afirmaciones que destaquen tanto la figura del sacerdote. En ellas ha podido influir la relativización que el Vaticano II hizo de la importancia de los sacerdotes en la vida de la Iglesia. El Concilio enalteció el sacerdocio común de los fieles, igualó a presbíteros y laicos en el camino a la santidad y prestigió el matrimonio ${ }^{42}$.

Otros asuntos de Río que merecen ser mencionados son su aspiración a una formación integral de los seminaristas (espiritual, cultural, humana y pastoral); la importancia que da al conocimiento de la Sagrada Escritura (23); a la dirección espiritual de los seminaristas (12-13); a la necesidad de desarrollar vínculos de amistad y fraternidad entre ellos (23-25); al cultivo de las vocaciones sacerdotales desde temprana edad (5). Por otra parte, son de tener presentes algunas omisiones, como ser, que el documento nunca se refiere al «sacerdocio común de los fieles»; no dice una palabra sobre los estudios teológicos, filosóficos y científicos en general. En los textos referentes a la formación de los sacerdotes no se espera que éstos hagan suya la preocupación por atender a los problemas sociales de la época, aunque en otras partes del documento esta preocupación es grande.

\section{CONCLUSIÓN}

Vista en perspectiva, la recepción que las cuatro últimas conferencias generales del episcopado latinoamericano han hecho de OT ha sido compleja. Esta complejidad está asociada a enormes cambios culturales mundiales y a la realidad de la Iglesia latinoamericana en las últimas décadas en particular. La Iglesia, y el clero especialmente, ha experimentado

41 Cf. J. P. Haran, SJ. "Minister Christi Sacerdos”. Theological Studies 8, n. ${ }^{\circ} 2$, (1947): 251-279; R. Garrigou-Lagrange. De unione sacerdotis cum Christo sacerdote et victi: cursus theologiae spiritualis pro sacerdotibus. Taurini-Romae: Marietti, 1948, 158.ma

42 En OT, sin embargo, pervivió la teología de los «estados de perfección». Afirma el decreto: «Los alumnos han de conocer debidamente las obligaciones y la dignidad del matrimonio cristiano que simboliza el amor entre Cristo y la Iglesia; convénzanse, sin embargo, de la mayor excelencia de la virginidad consagrada a Cristo, de forma que se entreguen generosamente al Señor, después de una elección seriamente premeditada y con entrega total de cuerpo y alma» (10; cf. 2). 
cambios históricos que van desde el impacto de la Revolución cubana a la crisis del coronavirus, pasando por las dictaduras militares, la superación y la vuelta a la pobreza, y la estremecedora crisis de confianza en los sacerdotes y los obispos a causa de los abusos sexuales del clero y sus encubrimientos.

Gracias a la visión que dan los años, la recepción que los documentos de las conferencias han hecho de OT debe ser vinculada especialmente al gran empeño evangelizador que desencadenó un concilio pastoral. Sabemos que esta característica provenía de los consilia et vota que los obispos hicieron llegar a Roma antes de la celebración del Concilio. Medellín quiso dar un giro de la "sacramentalización» a la "evangelización»; Puebla pretendió hacer suya Evangelii nuntiandi; Santo Domingo se sumó a la «nueva evangelización» impulsada por Juan Pablo II; y Aparecida demandó de la Iglesia volverse misionera.

¿Qué tipo de sacerdote ha podido responder a esta necesidad evangelizadora? Si antes y después del Concilio se ha lamentado una escasez de sacerdotes, el Vaticano II fomentó la formación de éstos de acuerdo a su nueva manera de entender el anuncio de la Palabra en el mundo actual. Sin embargo, no es claro que el Concilio haya generado las condiciones formativas suficientes para hacer de los seminaristas ministros capaces de desenvolverse en sociedades agitadas por problemas sociales y en creciente secularización. El desafío ha sido mayor. Por cierto, en lo que va de estos años, la Iglesia latinoamericana no ha hecho suyo, según parece, el mandato de Medellín de formar seminaristas capaces de discernir los signos de los tiempos. Por el contrario, los católicos a poco andar de las innovaciones han constatado una resacralización de los ministros. Hoy nuevamente se los percibe separados de la gente y del mundo, en vez de insertos en la realidad para comprenderla y anunciar el Evangelio haciendo de éste una auténtica buena noticia.

Si atendemos sólo a los documentos investigados es posible registrar un movimiento de diástole y sístole. De Medellín a Aparecida éstos reflejan una diferencia importante. Si en Medellín advertimos una expansión y apertura al mundo, en Aparecida, por el contrario, notamos un cuidado ante éste y un repliegue eclesiástico. El sacerdote que la V Conferencia ha querido preparar para ser misionero no ha sido el que Medellín quiso capacitar para interpretar los signos de los tiempos. Tampoco ha sido el ministro de la Palabra propuesto por PO y OT. 
En el estudio de los textos hemos constatado una recepción difícil de valorar. Aun cuando deba reconocerse a las cuatro últimas conferencias una voluntad de acogida de OT, se acusa en ellas una progresiva regresión respecto de la innovación conciliar. A propósito de la formación del clero latinoamericano no puede decirse que la Iglesia del continente haya hecho una recepción "creativa» del Vaticano $\mathrm{II}^{43}$. Por cierto, debe considerarse meritorio que Medellín haya querido abrir a los seminaristas a la realidad histórica y a reconocer en ella la voz de Dios. Haciendo así, obedecía el mandato pastoral del Vaticano II. En esta apertura, los formandos han debido exponerse a estos cambios y hacer suyas las inquietudes especialmente sociales de sus contemporáneos. Pero hemos visto que en el documento de Medellín hay también olvidos importantes que pudieron haber dificultado su aceptación por las siguientes conferencias, por las normas para la formación de las iglesias locales y en la práctica misma de los seminarios. Medellín, en vez de repetir lo dicho en los documentos conciliares, prefirió enfocarse en aquello que quiso priorizar. Pero bien pudo recordar algunos asuntos fundamentales y no lo hizo.

Treinta y nueve años después, Aparecida, en los pocos números que dedicó al tema, ofreció a la formación una imagen negativa de mundo. Si en Medellín el mundo por delante debía ser el texto en el que discernir la presencia y la voluntad de Dios, en Aparecida el mundo es de temer. Es así que, en los años sucesivos a la V conferencia, los seminaristas debieron ser formados para soportar un medio socio-cultural adverso. Pero lo más preocupante de esta última conferencia en relación a OT, es que en ella se registra el influjo de Pastores dabo vobis en perjuicio tanto de OT como de PO. El giro conciliar más importante en la materia había sido desplazar el ministerio del culto a un segundo lugar, reconociéndose que

43 Segundo Galilea suele ser citado por caracterizar la recepción del Concilio de un modo positivo. Convendría analizar en profundidad si su modo general de entender la acogida del Vaticano II corresponde a algunos, a la mayoría o a todos los asuntos (Segundo Galilea. "Ejemplo de recepción selectiva y creativa del Concilio: América Latina en las conferencias de Medellín y Puebla”. En La recepción del Vaticano II, dirigido por G. Alberigo y J. P. Jossua, 86-101. Madrid, 1987; cf. Luis Martínez. "La recepción creativa del Concilio Vaticano II en América Latina: Implicaciones para la

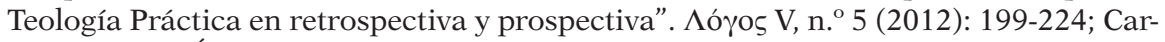
los Mendoza-Álvarez. "La teología de la liberación en México: recepción creativa del Concilio Vaticano II”. Theologia Xaveriana 64, n. 177 (2014): 157-79; Miguel Concha Malo. "Apuntes sobre la recepción creativa del concilio ecuménico Vaticano II por la iglesia de América Latina y El Caribe”. Voces 20, n. 38 (2013): 85-107. 
«los presbíteros, como colaboradores que son de los obispos, tienen por deber primero el de anunciar a todos el Evangelio de Dios» (PO 4). El Concilio reordenó la secuencia de los tria munera. No habría de hablarse más del presbítero como de un sacerdote, profeta y rey, sino de un profeta, sacerdote y rey; y de una compenetración de estas dimensiones del ministerio al servicio de la misión de la Iglesia. En este paso, que muchos han podido no advertir, se puede adivinar el movimiento de introversión de la Iglesia latinoamericana de las últimas décadas. El impulso misionero que Aparecida quiso dar a la Iglesia ha podido ser liderado por un clero que, en realidad, ha estado más preocupado de celebrar la eucaristía que de aprender de los tiempos y ayudar a sus contemporáneos a leer en los acontecimientos la Palabra de Dios.

Puebla y Santo Domingo, vistas los acontecimientos en perspectiva, pueden considerarse documentos de transición. La conferencia de Puebla continuó la de Medellín, atemperando su extraordinaria novedad, y Santo Domingo anticipó el repliegue de Aparecida. La tercera conferencia aún orientó la formación de los seminaristas para hacerse cargo de la realidad y la cuarta, en cambio, quiso hacer suyo Pastores dabo vobis.

Independientemente de lo anterior, esta investigación ha detectado que ninguna de las cuatro conferencias tomó en serio el mandato de OT acerca de los estudios de los seminaristas. El decreto conciliar pidió establecer una estrecha relación entre la teología y la filosofía. Los documentos latinoamericanos prácticamente no mencionan la teología. ¿Descansaron los obispos en que sería una vez más la teología europea la que surtiría la formación de los seminaristas latinoamericanos? Es cierto que la Iglesia latinoamericana no tuvo teología propia antes del Vaticano II y, por ende, todavía tuvo que depender de la europea. Pero, al menos en las secciones que las conferencias han dedicado a la formación, no se ha dado ningún reconocimiento a la teología latinoamericana desarrollada después del Concilio. Pues bien, ¿cómo habrían de dialogar los sacerdotes latinoamericanos con su época sin instrumentos teóricos indispensables? Al menos Medellín, la primera conferencia responsable de recibir el concilio, debió señalar que para el reconocimiento de los siglos de tiempos, eran necesarios estudios teológicos, filosóficos y sociológicos serios.

Acusamos un último déficit. Si por recepción entendemos en primer lugar la acogida del Evangelio, la formación de los seminaristas también debe ser puesta en relación con la recepción general que la Iglesia en América Latina ha hecho del Vaticano II en los años que ella ha hecho un 
esfuerzo por discernir sus signos de los tiempos. A resultas de este ejercicio, si se trata de hablar en términos simbólicos, esta recepción lleva el nombre de opción por los pobres. Pues bien, si la cuna de esta expresión fueron Medellín y Puebla, si las conferencias de Santo Domingo y Aparecida la ratificaron, ¿por qué no se encaminó explícitamente la formación de los seminaristas por esta senda? De haberlo hecho, la inserción de los presbíteros en los medios populares habría sido más profunda y, por ende, más evangelizadora.

\section{REFERENCIAS}

Acta Synodalia Sacrosancti Concilii Oecumenici Vaticani II. Typis Polyglottis Vaticanis, 1973. Analyticus conspectus consiliorum.

Aldunate, José. "Recepción del Concilio Vaticano II por la Iglesia Chilena”. Reflexión y liberación 26, n. ${ }^{\circ} 107$ (2015): 16-21.

Angelelli, Enrique. Acta Synodalia Sacrosancti Concilii Oecumenici Vaticani II. Typis Polyglottis Vaticanis, 1973.

Arce, Richard. "Concilio Vaticano II - 50 años: el proceso de su recepción en América Latina”. Nuevamérica n. ${ }^{\circ} 137$ (2013): 24-29.

Azcuy, Virginia. "La recepción del Concilio Vaticano II en el pueblo de Dios. Testimonios sobre la renovación desde las formas de vida". Revista Teología 50, n. ${ }^{\circ} 112$ (2013): 203-49. https://repositorio.uca.edu. ar/handle/123456789/7173

Barbieri, Antonio. Acta Synodalia Sacrosancti Concilii Oecumenici Vaticani II. Typis Polyglottis Vaticanis, 1973.

Bonino, J. Míguez. "The Reception of Vatican II in Latin America”. Oicumene 37, n. 3 (1985): 266-74. https://doi.org/10.1111/j.1758-6623.1985. tb01317.x

Brighenti, Agenor. "Vaticano II - Medellín : intuições básicas e eixos fundamentais". Revista eclesiástica brasileira 69, n. ${ }^{\circ} 273$ (2009): 5-26. https://doi.org/10.29386/reb.v69i273.1369

Codina, Víctor. "Recepción del Concilio Vaticano II en América Latina”. Mensaje 62, n. ${ }^{\circ} 625$ (2013): 28-29.

Concha Malo, Miguel. "Apuntes sobre la recepción creativa del concilio ecuménico Vaticano II por la Iglesia de América Latina y El Caribe". Voces 20, n. ${ }^{\circ} 38$ (2013): 85-107. 
Conferencia de obispos de México. Acta Synodalia Sacrosancti Concilii Oecumenici Vaticani II. Typis Polyglottis Vaticanis, 1973.

Coppe Caldeira, Rodrigo. "O Concílio Vaticano II, sua hermenêutica e recepção”. Estudos teológicos 55, n. ${ }^{\circ} 1$ (2015): 60-75.

Costadoat, J., SJ. "La formación teológica en América Latina antes del Concilio". Estudios Eclesiásticos 95, n. 373 (2020): 441-455. https:// doi.org/10.14422/ee.v95.i373.y2020.006

Costadoat, J., SJ. "Contribución de los obispos latinoamericanos a la confección de Optatam totius". Teología y Vida 62, n. ${ }^{\circ} 3$ (2021): 389-423. https://doi.org/10.7764/TyV/623/3/389-423

De Alba y Hernández, Ignacio. Acta Synodalia Sacrosancti Concilii Oecumenici Vaticani II. Typis Polyglottis Vaticanis, 1973.

Galilea, Segundo. "Ejemplo de recepción selectiva y creativa del Concilio: América Latina en las conferencias de Medellín y Puebla". En La recepción del Vaticano II, dirigido por G. Alberigo y J. P. Jossua, 86-101. Madrid, 1987.

Garrigou-Lagrange, R. De unione sacerdotis cum Christo sacerdote et victima: cursus theologiae spiritualis pro sacerdotibus. Taurini-Romae: Marietti, 1948.

Guerrero, Alfonso. "La recepción del Concilio en América Latina". Iter n. ${ }^{\circ} 1$ (1995): 35-46.

Haran, J. P. "Minister Christi Sacerdos". Theological Studies 8, n. ${ }^{\circ} 2$ (1947): 251-279. https://doi.org/10.1177\%2F004056394700800203

Hartl, Carlos. Acta Synodalia Sacrosancti Concilii Oecumenici Vaticani II. Typis Polyglottis Vaticanis, 1973.

Kaplan, Grant. "The renewal of ecclesiastical studies: Chenu, Tübingen, and Theological Method in Optatam totius". Theological Studies 77, n. ${ }^{\circ}$ (2016): 567-592. https://doi.org/10.1177/0040563916653090

Legorreta Zepeda, José de Jesús. "La recepción latinoamericana del Concilio en los documentos de las conferencias generales del episcopado latinoamericano: de Medellín a Aparecida". Christus 77, n. ${ }^{\circ} 802$ (2014): 11-20.

Luciani, Rafael. "Medellín fifty years later: From development to liberation". Theological Studies 79, n. ${ }^{\circ} 3$ (2018): 566-89. https://doi. org/10.1177/0040563918784765

Marengo, Manuel. Acta Synodalia Sacrosancti Concilii Oecumenici Vaticani II. Typis Polyglottis Vaticanis, 1973. 
Martínez, Luis. "La recepción creativa del Concilio Vaticano II en América Latina: Implicaciones para la Teología Práctica en retrospectiva y prospectiva”. \óyos V, n. ${ }^{\circ} 5$ (2012): 199-224.

Mauti, Ricardo. "La recepción de Optatam totius en las rationes de la Iglesia de América Latina”. En vías de publicación.

Mendoza-Álvarez, Carlos. "La teología de la liberación en México: recepción creativa del Concilio Vaticano II". Theologia Xaveriana 64, n. ${ }^{\circ} 177$ (2014): 157-79.

Pelton, Robert. "The reception of Vatican II in Latin America: A North American perspective". Theological Studies 74, n. ${ }^{\circ} 4$ (2013): 819-27. https://doi.org/10.1177/004056391307400404

Pironio, Eduardo. Acta Synodalia Sacrosancti Concilii Oecumenici Vaticani II. Typis Polyglottis Vaticanis, 1973.

Polanco, Rodrigo. "Concepto teológico de recepción con vistas a su aplicación al desarrollo posterior al Concilio Vaticano II". Teología y vida 54 (2013): 205-31. http://dx.doi.org/10.4067/S0049-34492013000200002

Routhier, Gilles. "L'écho de l'enseignement de Vatican II sur le prestytérat dans la situation actuelle". Revue Théologique de Louvain 41 (2010): 86-112. https://doi.org/10.2143/RTL.41.1.2045861

Sagrada Congregación para la Educación Católica. "Normas básicas para la formación sacerdotal”. Roma, 1970.

Scampini, Jorge A., y Carlos Federico Schickendantz. La recepción teológica del Concilio Vaticano II. Buenos Aires: Agape-Guadalupe, 2015.

Senner, Juan T. Acta Synodalia Sacrosancti Concilii Oecumenici Vaticani II. Typis Polyglottis Vaticanis, 1973.

Silva Santiago, Alfredo. Acta Synodalia Sacrosancti Concilii Oecumenici Vaticani II. Typis Polyglottis Vaticanis, 1973.

Silva, Eduardo. "Paul Ricoeur y los desplazamientos de la hermenéutica". Teología y vida 46, n. ${ }^{\circ}$ 1-2 (2005): 191-196. http://dx.doi.org/10.4067/ S0049-34492005000100008

Suess, Paulo. "Sinais dos tempos". En Dicionário do Concílio Vaticano II, 895-901. São Paulo, 2015.

Taborda, Francisco. "A conferencia de Medellín como recepção do Vaticano II". Perspectiva Teológica 51, n. ${ }^{\circ} 1$ (2019): 115-32. https://doi.org/ 10.20911/21768757v51n1p115/2019

Trigo, Pedro. "Recepción del Vaticano II a los cincuenta años de su apertura". Iter 23, n. ${ }^{\circ}$ 57-58 (2012): 15-23. 
Valiente, Ernesto. "The reception of the Vatican II in Latin America". Theological Studies, n. ${ }^{\circ} 73$ (2012): 795-823. https://doi. org/10.1177/004056391207300403

Verdugo, Fernando. "Relectura de Medellín: desafíos actuales para la teología”. Teología y vida 59 (2018): 111-28. https://doi.org/10.4067/ s0049-34492018000100111 